\title{
Mansonella ozzardi in the municipality of Tefé, Amazonas, Brazil, 60 years after the first report: an epidemiologic study
}

\author{
Jansen Fernandes Medeiros ${ }^{1 /+}$, Moreno Souza Rodrigues ${ }^{1}$, Tony Hiroshi Katsuragawa ${ }^{2}$, \\ Cristóvão Alves Costa ${ }^{3}$, Felipe Arley Costa Pessoa ${ }^{4}$
}

\author{
${ }^{1}$ Laboratório de Entomologia ${ }^{2}$ Laboratório de Epidemiologia-Fiocruz, Porto Velho, RO, Brasil \\ ${ }^{3}$ Laboratório de Virologia, Instituto Nacional de Pesquisas da Amazônia, Manaus, AM, Brasil \\ ${ }^{4}$ Laboratório de Ecologia de Doenças Transmissíveis na Amazônia, Instituto Leônidas e Maria Deane-Fiocruz, Manaus, AM, Brasil
}

\begin{abstract}
The prevalence of mansonelliasis was studied in the municipality of Tefé, state of Amazonas, Brazil. The prevalence (thick blood smear method) was 13.6\% (147/1,078), higher in the Solimões River region (16.3\%) than in the Tefé River region (6.3\%). In the sampled communities in the Solimões River region, a higher density of cases was observed, as indicated by a kernel analysis (odds ratio 0.34; 95\% confidence interval: 0.20-0.57). Males had a higher prevalence $\left(\chi^{2}=31.292, p<0.001\right)$ than women. Mansonella ozzardi prevalence was higher in retirees and farmers $\left(28.9 \%\right.$ and $27 \%$, respectively). Prevalence also significantly increased with age $\left(\chi^{2}=-128.17, p<0.001\right)$, with the highest numbers occurring in persons older than 67 years.
\end{abstract}

Key words: filariasis - mansonelliasis - Mansonella ozzardi - Amazonia

Mansonella ozzardi is one of the etiological agents of mansonelliasis, an endemic filaria in the Americas and Caribbean Islands (Shelley \& Coscarón 2001). It is a poorly understood filarial species, without a welldefined pathogenicity, presenting asymptomatically or with few symptoms in infected individuals or with obvious clinical manifestations (fever, joint pain, adenitis, headache, coolness of the lower extremities) (Batista et al. 1960, Tavares 1981). In addition, corneal lesions have also been reported in possible association with the parasitic infection (Vianna et al. 2013). Certain symptoms are shared with other diseases, such as malaria, confusing the diagnosis in endemic areas. To date, only the Simuliidae have been identified as vectors in Brazil (Medeiros et al. 2009, Martins et al. 2010).

M. ozzardi has a broad distribution in the state of Amazonas (AM), Brazil. It is found along the Solimões and Purus Rivers and the Negro River and its tributaries (Rachou 1957, Medeiros et al. 2009, Martins et al. 2010). Since the first records of its occurrence, it has been observed that the prevalence remains high in certain areas (Solimões River, municipality of Coari: 10\% and 18.4\%) (Rachou 1957, Martins et al. 2010), whereas sudden increases have occurred in other areas (Purus River, municipality of Boca do Acre: $0.2 \%$ and $27.3 \%$; municipality of Lábrea: $0.4 \%, 4.4 \%$ and $20.7 \%$ ) (Rachou 1957, Shelley 1975, Medeiros et al. 2009, 2011).

This study was conducted in the middle Solimões River region in the municipality of Tefé, AM. This is an

doi: 10.1590/0074-0276130512

Financial support: FAPEAM (PPSUS 007/2009)

+ Corresponding author: jmedeiro@gmail.com

Received 24 October 2013

Accepted 10 January 2014 endemic region for M. ozzardi. The parasite was found during an epidemiological investigation in the $1950 \mathrm{~s}$ that demonstrated prevalence between $2.5 \%$ and $18.7 \%$ (Rachou 1957). Due to the presence of oil and natural gas extracting companies, there is a continuous flow of population into this municipality from several Brazilian areas. Such human movement may allow the filaria to spread to nonendemic areas. Given this information, a broad inquiry was made in the region of the Solimões and Tefé Rivers to provide an updated epidemiological profile of M. ozzardi in Tefé.

This study was performed in 29 rural communities selected with the convenience sampling method in the Solimões and Tefé River regions in Tefé $\left(3^{\circ} 21^{\prime} \mathrm{S}\right.$ $64^{\circ} 43^{\prime} \mathrm{W}$ ) (Fig. 1A). The municipality has 61,453 inhabitants (urban population $=50,069,81.5 \%$; rural population $=11,384,18.5 \%)($ IBGE 2010). The region is covered by native primary forest and has extensive flooded areas during the rainy season. Rural populations are located along the rivers in small villages. The economic base of these small communities consists of fishing, agriculture and livestock farming. The required sample size was calculated on the basis of an estimated M. ozzardi prevalence of $18.4 \%$ (Martins et al. 2010), an error of $20 \%$ and a confidence interval (CI) of 95\%. Individuals participated in this study after giving informed consent. Within each community, individuals three years of age or older who underwent blood sampling were included. In total, 1,083 individuals ( $9.5 \%$ of the rural population) were examined by the Rapid Epidemiological Mapping test for microfilariae of M. ozzardi in April, August, September, October and November of 2012. We collected demographic (age, gender and profession) and geographic data (name of the village and geographical location).

M. ozzardi prevalence was measured by thick blood smears obtained by digital puncture. Two drops of blood (approximately $60 \mu \mathrm{L}$ ) were collected from each individual and placed on a slide. After air-drying, the slides were 
stained with Giemsa and observed under light microscopy (200X/400X magnification). If the blood smears were positive, the mf was identified following Post et al. (2003). Additionally, M. ozzardi mf were also submitted to a new identification protocol using the polymerase chain reaction (SLB Luz, unpublished observations). The study protocol was approved by the Research Ethical Committee of the Tropical Medicine Foundation Dr Heitor Vieira Dourado (protocol 1504/10), in Manaus, AM. Informed consent was obtained from all adults and from the parents of the minors who participated in the study.

The data were analysed using Generalised Linear Models with $\mathrm{R}$ software ( $\mathrm{R}$ Development Core Team 2010). To verify the differences in the prevalence of $M$. ozzardi between genders, activities and age groups, we performed an ANOVA followed by an analysis of contrasts as appropriate. Furthermore, odds ratios (OR) and 95\% CI were determined for each group using Epicalc. Kernel mapping was used to analyse the spatial distribution of the intensity and prevalence of cases and to identify high-risk areas (hot spots) for M. ozzardi.

In total, 1,083 individuals were examined (average age $28.3 \pm 19.5$, range 3-93 years) in 29 communities on the Solimões and Tefé Rivers, representing 9.5\% of the rural population of Tefé. The male:female ratio was 0.80 (484/1,083: 44.7\% male; 599/1,083: 55.3\% female).

The overall prevalence of $M$. ozzardi was $13.5 \%$ $(147 / 1,083)$. The prevalence in the Solimões River communities was $16.3 \%(128 / 783)$, whereas it was $6.3 \%$ $(19 / 300)$ in the Tefé River communities, a significant difference (ANOVA: $\chi^{2}=23.259, \mathrm{p}<0.001$ ). A kernel analysis indicated that the areas with a higher intensity and prevalence of cases were located near the Solimões River (Fig. 1B, C); the Solimões River also had a higher OR relative to the Tefé River (OR: 0.34 ; 95\% CI: 0.20 0.57) (Fig. 2A). In the area of the Solimões River, in contrast to the Tefé River, the communities are larger and closer to each other, with a higher population density. This proximity favours a higher transmission rate of filariae by Simuliidae. The higher prevalence in the Solimões River area is facilitated by the presence in the area of the simuliid black fly Cerqueirellum argentiscutum, which transmits the parasite in the area (Martins et al. 2010). Those observations are strengthened by the finding that the risk ratio was higher in the Solimões River area and by the kernel analysis, which showed hot spots in the Solimões River communities. The prevalence $(16.3 \%)$ in the Solimões River communities in Tefé is close to that found along the same river in Coari, between 17.1-17.8\% (Rachou 1957) or 18.4\% (Martins et al. 2010) and in Codajás, where the prevalence was $23.9 \%$ (Rachou 1957). In certain communities, the prevalence is still high after several decades. In Missão, Caiambé and Jutica, the prevalence found by this study was $11.3 \%, 18.2 \%$ and $30 \%$, respectively. Previously, the prevalence was $13.3 \%, 17.5 \%$ and $18.7 \%$, respectively (Rachou 1957). Similar findings were obtained in other municipalities of AM: in Coari, during the 1950s, it was $10 \%$ and it was $17.1 \%$ and $17.8 \%$ in the river communities (Rachou 1957). More recently, prevalence of $10.2 \%$ was found for urban zona of Coari and 18.4\% and 26.4\% for the river communities (Martins et al. 2010, Vianna et al. 2013). In the Purus River municipalities, such as Lábrea, prevalence of $0.4 \%, 4.4 \%$ and $5.9 \%$ were found (Rachou 1957, Shelley 1975, Tavares 1981) and, more recently, 30.2\% and 20.7\% (Medeiros et al. 2008, 2011). The stability and increase in prevalence found both in Tefé and others municipalities over the years is primarily a result of a lack of treatment policies, resulting in persistent infection rates and continuous transmission. It is possible that this permanent transmission cycle maintains the stability of infection because many individuals may become infected repeatedly over time, resulting in permanent microfilaria production and compensating for
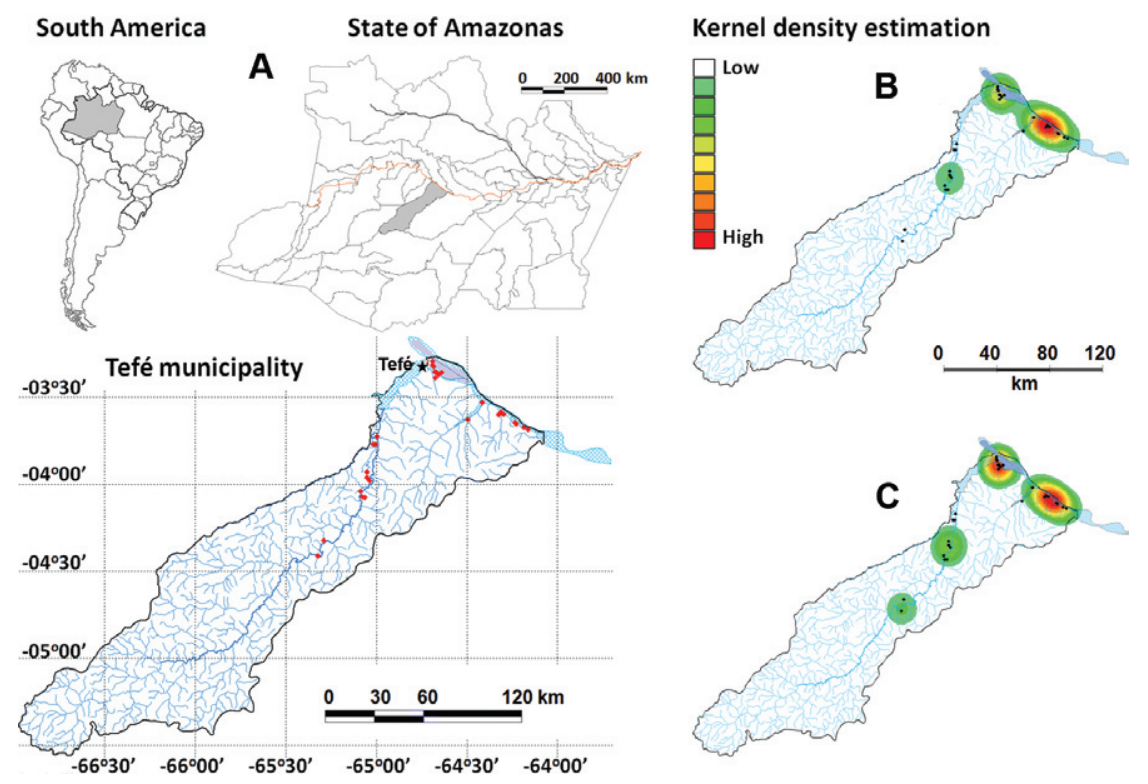

Fig. 1A: map of study area location. The red points indicate study localities. The black star indicates the municipality of Tefé, state of Amazonas, Brazil; B: Kernel density estimation for cases; C: Kernel density estimation for prevalence. 


\section{TABLE}

Mansonella ozzardi prevalence by gender, age group, occupation and risk factors for filaria in the municipality of Tefé, state of Amazonas, Brazil

\begin{tabular}{|c|c|c|c|c|}
\hline \multirow[b]{2}{*}{ Variable } & & \multirow{2}{*}{$\begin{array}{l}\text { Positive/total } \\
{[\mathrm{n} / \mathrm{n}(\%)]}\end{array}$} & \multicolumn{2}{|c|}{ ANOVA } \\
\hline & & & $\mathrm{p}$ & Analyse of contrast \\
\hline Total & & 147/1,083 (13.5) & & - \\
\hline \multirow[t]{2}{*}{ Gender } & Female & $51 / 599(8.5)$ & $\mathrm{p}<0.001$ & - \\
\hline & Male & $96 / 484(19.2)$ & & - \\
\hline \multirow[t]{8}{*}{ Age group (years) } & $2-9$ & 3/178 (1.6) & & $\mathrm{a}$ \\
\hline & $10-18$ & $15 / 271(5.5)$ & $\mathrm{p}<0.001$ & $\mathrm{~b}$ \\
\hline & $19-27$ & $15 / 164(9.1)$ & & $\mathrm{b}$ \\
\hline & $28-37$ & 28/159 (17.6) & & $\mathrm{c}$ \\
\hline & $38-47$ & 23/107 (21.5) & & $\mathrm{c}$ \\
\hline & $48-57$ & 26/91 (28.6) & & $\mathrm{c}$ \\
\hline & $58-67$ & $18 / 63(28.6)$ & & $\mathrm{c}$ \\
\hline & $>67$ & $19 / 50(38)$ & & d \\
\hline \multirow[t]{5}{*}{ Activity } & Farmer/fisherman & $69 / 255(27)$ & $\mathrm{p}<0.001$ & $\mathrm{a}$ \\
\hline & Housewife & $30 / 232(12.9)$ & & $\mathrm{b}$ \\
\hline & Student & $18 / 437(4.1)$ & & $\mathrm{c}$ \\
\hline & Retired & 24/83 (28.9) & & $\mathrm{d}$ \\
\hline & Other & $6 / 76(7.9)$ & & $\mathrm{b}$ \\
\hline
\end{tabular}

different letters indicates statistical difference $(\mathrm{p}<0.05)$.
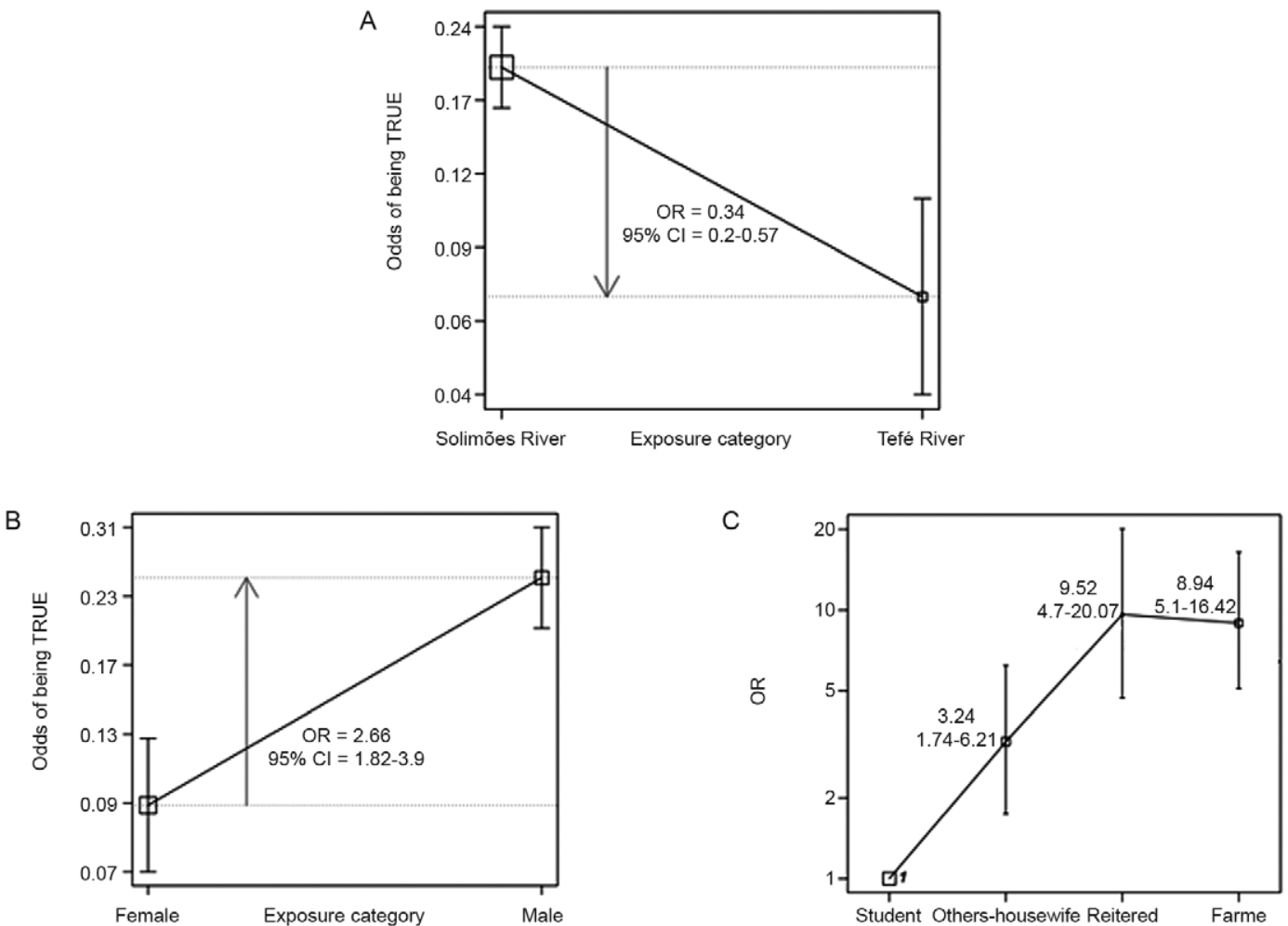

Fig. 2: odds ratio (OR) between Solimões and Téfe Rivers (A), between gender (B) and among different occupations (C) in the municipality of Tefé, state of Amazonas, Brazil. CI: confidence interval. 
the decreased fertility and mortality of older worms. The lifespan and reproductive cycle of adult $M$. ozzardi are unknown. However, Orihel et al. (1993) observed that in monkeys, infection can persist for up to 212 weeks and that microfilaremia constantly increased at the beginning of infection, reaching its highest level at 20 weeks and then slowly decreasing to stable levels for up to 48 weeks. Subsequently, microfilariae disappeared from the blood and occasionally reappeared in low numbers.

M. ozzardi was significantly higher in males than in females (Table) (ANOVA: $\chi^{2}=31.292, p<0.001$ ). Furthermore, the prevalence of infection also differed significantly among age groups. An analysis of contrasts identified four groups: group 1 (0-9 years), group 2 (1027 years), group 3 (28-67 years) and group 4 ( $>67$ years) (ANOVA: $\chi^{2}=-117.11, p<0.001$ ). A significant difference was found in $M$. ozzardi prevalence between different occupations (ANOVA: $\chi^{2}=-105.37, p<0.001$ ), with the highest prevalence in retirees and farmers $(28.9 \%$ and $27 \%$, respectively). The OR analyses for each variable (i.e., gender, occupation and age group) indicated the following: (i) men had a higher risk ratio than women (OR: 2.66; 95\% CI: 1.82-3.90) (Fig. 2B), (ii) according to occupation, the highest risk of acquiring the infection was in retirees (OR: 9.52, 95\% CI: 4.70-20.07) (Fig. 2C) and individuals older than 67 years had a high OR relative to all other age groups (OR: 33.89, CI 95\%: 9.21-189.33).

The difference between genders is due to the higher exposure of males to simuliid bites, a consequence of occupational exposure, as observed by other authors (Medeiros et al. 2009, 2011, Martins et al. 2010, Adami et al. 2014). The degree of exposure to vectors is also the factor that directly influences prevalence levels by age group, indicating that infection levels normally increase proportionally with age (Bartoloni et al. 1999, Medeiros et al. 2011). This trend was confirmed in our study by the comparative analysis and OR, which demonstrated that individuals older than 67 years had a risk ratio up to eight times higher than that in other age groups. Finally, in terms of working activity, the high prevalence found in retired people may be related to occupation because most are farmers and normally continue working even after retirement, with continued exposure and multiple opportunities for reinfection. Multiple exposures to reinfection are also reflected by age; the older the person is, the higher the risk of carrying the infection. Bartoloni et al. (1999) suggests that the high level of microfilaremia in adults is due to the continuous succession of superimposed infections. This hypothesis is strengthened by observations by other authors (Martins et al. 2010, Medeiros et al. 2011) that also demonstrated a higher prevalence in farmers and retirees.

This paper confirms that the prevalence in Tefé is still high even after 60 years based on the same diagnostic method used by Rachou (1957). If more sensitive methods, such as the Knott method and molecular diagnostics, were used, the observed prevalence should be much higher. In Codajás, for example, the prevalence based on blood films was $23.5 \%$, but the observed prevalence increased to $41.4 \%$ when the Knott method was used (Moraes 1958).

\section{ACKNOWLEDGEMENTS}

To the Foundation for Health Surveillance of Tefé, for logistical support, and to José Jonas Nascimento da Rocha, Ricardo de Moura Mota and Elbion de Oliveira Moraes, for assistance during field work.

\section{REFERENCES}

Adami YL, Rodrigues G, Alves MC, Moraes MAP, Banic DM, MaiaHerzog M 2014. New records of Mansonella ozzardi: a parasite that is spreading from the state of Amazonas to previously uninfected areas of the state of Acre in the Purus River region. Mem Inst Oswaldo Cruz 109: 87-92.

Bartoloni A, Cancrini G, Bartalesi F, Marcolin D, Roselli M, Arce CC, Hall AJ 1999. Mansonella ozzardi infection in Bolivia: prevalence and clinical associations in the Chaco Region. Am J Trop Med Hyg 61: 830-833.

Batista D, Oliveira WR, Rabello VD 1960. Estudo da patogenicidade da Mansonella ozzardi e da sintomatologia da mansonelose. Rev Inst Med Trop Sao Paulo 2: 281-289.

IBGE - Instituto Brasileiro de Geografia e Estatística 2000. População e domicílios - Censo 2010. Available from: ibge.gov.br.

Martins M, Pessoa FAC, de Medeiros MB, de Andrade EV, Medeiros JF 2010. Mansonella ozzardi in Amazonas, Brazil: prevalence and distribution in the municipality of Coari, in the middle Solimões River. Mem Inst Oswaldo Cruz 105: 246-253.

Medeiros JF, Py-Daniel V, Barbosa UC 2011. Prevalence of Mansonella ozzardi among riverine communities in the municipality of Lábrea, Amazonas state, Brazil. Rev Soc Bras Med Trop 44: 186-190.

Medeiros JF, Py-Daniel V, Barbosa UC, Ogawa GM 2008. Current profile of Mansonella ozzardi (Nematoda: Onchocercidae) in communities along the Ituxi River, Lábrea municipality, Amazonas, Brazil. Mem Inst Oswald Cruz 103: 409-411.

Medeiros JF, Py-Daniel V, Barbosa UC, Ogawa GM 2009. Ocorrência da Mansonella ozzardi (Nematoda, Onchocercidae) em comunidades ribeirinhas do Rio Purus, município de Boca do Acre, Amazonas, Brasil. Cad Saude Publica 25: 1421-1426.

Moraes MAP 1958. Contribuição ao estudo da mansonelose do Amazonas. Hospital 54: 887-892.

Orihel TC, Eberhard ML, Lowrie Jr RC 1993. Mansonella ozzardi: the course of the patency in experimentally infected patas monkeys. Trop Med Parasitol 44: 49-54.

Post RJ, Adams ZA, Shelley AJ, Maia-Herzog M, Dias APAL, Coscarón S 2003. The morphological discrimination of microfilariae of Onchocerca volvulus from Mansonella ozzardi. Parasitology 127: 21-27.

R Development Core Team 2010. R: a language and environment for statistical computing. Available from: r-project.org.

Rachou RG 1957. Distribuição geográfica das filarioses humanas no Brasil. Rev Bras Malariol Doencas Trop 9: 79-100.

Shelley AJ 1975. A preliminary survey of the prevalence of Mansonella ozzardi in some rural communities on the Purus River, state of Amazonas, Brazil. Ann Trop Med Parasitol 69: 407-412.

Shelley AJ, Coscarón S 2001. Simuliid blackflies (Diptera: Simuliidae) and ceratopogonidmidges (Diptera: Ceratopogonidae) as vectors of Mansonella ozzardi (Nematoda: Onchocercidae) in northern Argentina. Mem Inst Oswaldo Cruz 96: 451-458.

Tavares AM 1981. Estudo da infecção por Mansonella ozzardi, MsD Thesis, Universidade de Brasília, Brasília, 122 pp.

Vianna LMM, Martins M, Cohen MJ, JM Cohen, Belfort Jr R 2013. Mansonella ozzardi corneal lesions in the Amazon: a cross-sectional study. BMJ Open 2: e001266. 